\title{
SOBRE A QUESTÃO DAS FRAÇÕES DE CLASSE DOMINANTE
}

\author{
FRANCISCO PEREIRA DE FARIAS ${ }^{1}$
}

Este trabalho ${ }^{2}$ pode ser útil para avaliar uma subtese presente no campo da teoria das classes sociais, segundo a qual o capitalismo contemporâneo teria abolido as diferenças entre as frações do capital, tese essa exposta, por exemplo, no trabalho de Jorge Miglioli, "Globalização: uma nova fase do capitalismo?" ". A avaliação dessa subtese requer, segundo nossa compreensão, que fatos atuais como a existência de conglomerados econômicos multifuncionais ou de empresas transnacionais, sejam considerados em um contexto teórico mais preciso.

${ }^{1}$ Doutorando em Ciências Sociais no Instituto de Fiolosofia e Ciências Humanas (IFCH), da Universidade Estadual de Campinas (Unicamp) e docente do Departamento de Ciências Sociais da Universidade Federal do Piauí (UFPI).

2 O objeto desta exposição - os fracionamentos da classe dominante - é o tema tratado em reuniões de trabalho com Professor Doutor Décio Saes. Nesta comunicação, vou apresentar o que me parecem ser as principais proposições formuladas nessas reuniões sobre a temática. Foi discutido por nós um conjunto das obras de Nicos Poulantzas, selecionadas em função de propiciarem uma elaboração mais abrangente do tema. As obras selecionadas foram: Pouvoir politique et classes sociales, Paris, Maspero, 1968; Les classes sociales dans le capitalisme aujourd'hui, Paris, Seuil, 1974; Fascisme et dictature, Paris, Maspero, 1970; La crise des dictatures, Paris, Seuil, 1976. Os erros e imperfeições do presente texto serão de minha exclusiva responsabilidade.

3 J. Miglioli, “Globalização: uma nova fase do capitalismo?” In: Critica marxista, São Paulo: Boitempo, 1996, no 3.

62 SOBRE A QUESTÃO DAS FRAÇÕES DE CLASSE DOMINANTE 
Podemos inicialmente nos perguntar quais seriam as questões centrais para uma teoria do fracionamento da classe dominante. Diríamos que elas são fundamentalmente duas.

A primeira é a questão das condições que possibilitam o fracionamento da classe dominante. Em outros termos, seria necessário identificar o que torna possível a criação de linhas virtuais de conflitos no interior da classe dominante. Nesse campo, pode-se apontar os conflitos entre as frações burguesas, diferenciadas segundo as funções do capital (capital produtivo ou industrial, capital da esfera da circulação ou capitais comercial e bancário); segundo a escala do capital (grande capital, médio capital); segundo a inserção no mercado (capital monopolista, capital não-monopolista) e outras tantas dimensões de diferenciação. A resposta à questão dos fundamentos do fracionamento deve certamente estabelecer um número limitado de subsistemas de frações.

A segunda questão a ser considerada quanto ao fracionamento da classe dominante é a de identificar o mecanismo que converte os conflitos potenciais das frações em uma realidade factual. Noutras palavras, a questão consiste em apontar os fatores que atuariam para existirem de fato as oposições entre as frações de classe. Com relação a esses fatores, uma dificuldade que se apresenta, entre outras, consiste em afastar a seguinte dúvida: seria possível antecipar no plano teórico (e não apenas fazer a descrição a posteriori de situações particulares) o mecanismo segundo o qual emerge o conflito de frações?

Podemos apontar algumas proposições em respostas às questões acima levantadas, que serão enunciadas aqui a título de hipóteses de pesquisa.

A primeira hipótese consiste em que as condições que possibilitam o fracionamento da classe dominante equivalem aos efeitos combinados das estruturas da totalidade social. Em outras palavras, os "espaços virtuais" dos conflitos de frações surgiriam da interseção entre os efeitos da estrutura econômica e da estrutura política.

Como sabemos, a tese do vínculo entre os efeitos (combinados) das estruturas da totalidade social e as frações de classe encontra-se proposta no 
livro de Poulantzas Poder político e Classes sociais. No entanto, Poulantzas tem dificuldade, nesse livro, de manter-se fiel ao critério de combinação dos efeitos das estruturas no que diz respeito aos fundamentos das ações de frações, na medida em que, para salvar a fórmula do I8 Brumário de Marx que se refere a uma "burguesia parlamentar", ele levanta a possibilidade da existência de frações exclusivamente no plano político (o que implicaria também admitir a existência de frações no plano exclusivamente econômico). Convém notar que o próprio Poulantzas procurou rejeitar a tese da fração estritamente econômica. Seria de se esperar portanto que ele tentasse refutar também a tese da fração exclusivamente política.

Nessa direção, podemos nos referir, embora de um modo sumário, ao argumento (cujos elementos para sua elaboração se encontram na obra de Poulantzas) de por que a economia não seria um fundamento suficiente para o fracionamento de classe. O sistema econômico indica certas diferenciações de interesses no interior da classe dominante. Mas tais diferenças poderiam não ser (ou não deveriam ser) o objeto de tensões e conflitos, porque a conversão (ou a legitimação) dessas diferenças - que são fundamentalmente desigualdades de rendimento - em objeto de disputas é resultado do entrecruzamento da desigualdade econômica com os efeitos da estrutura política. Na sociedade capitalista, o igualitarismo jurídico do Estado burguês gera a predisposição para uma luta pela igualização da taxa de lucros nos diferentes setores do capital. Sem considerar esse componente político-ideológico o igualitarismo jurídico - ficaria difícil entender por que os capitalistas não se acomodariam em aceitar as taxas diferenciadas de lucro nas várias esferas do capital.

Por outro lado, podemos nos perguntar também se a possibilidade das frações lutarem por interesses exclusivamente políticos seria compatível com a interpretação marxista da política. A noção de interesses políticos independentes (ou autônomos) encontra-se, por exemplo, no pensamento de tipo weberiano. Para essa corrente, os membros da burocracia do Estado constituiriam um grupo que defende, antes de mais nada, os próprios interesses políticos (burocráticos), e não estaria portanto comprometido de antemão com quaisquer interesses externos a si mesmo. Analogamente, a no- 
ção de fração exclusivamente política remete à idéia de uma parcela da classe dominante que deixaria de ter um vínculo necessário com os interesses econômicos dessa classe. Mas então a expressão "fração política de classe" se revelaria contraditória, pois sendo assimilada à noção de "burocracia estatal autônoma", chocar-se-ia com o pressuposto classista do Estado.

Portanto, em contraposição às noções de "fração econômica" ou "fração política", o procedimento mais coerente com a fundamentação estrutural das práticas sociais seria o de mostrar a fração de classe como um fato social total (com a interdependência das dimensões econômica e política).

Sobre o mecanismo que tornaria concretos os conflitos potenciais de frações, a nossa hipótese é que essa concretização se deve, em primeira instância, às medidas de política econômica e de política social do Estado. Em outras palavras, são as políticas governamentais que induzem à agregação dos interesses das frações dominantes. Tais políticas não apenas propiciam que certos conflitos emerjam na cena política e outros permaneçam latentes, como também articulam e hierarquizam esses interesses. Como há uma sucessão de medidas governamentais, a configuração dos alinhamentos de frações não pode ser vista como algo constante e pré-fixado.

Considerando-se um conjunto de políticas em um certo período, pode-se notar as suas múltiplas dimensões. É o caso da política econômica do regime militar brasileiro pós-1964. A sua política econômica ora destacava os interesses do grande capital monopolista em oposição aos do médio capital não-monopolista (com uma legislação favorável à concentração e centralização de capital), ora ressaltava os interesses do capital bancário frente aos do capital industrial (com uma orientação monetarista da economia), ora opunha ainda os interesses de uma burguesia interna aos do capital estrangeiro (com uma resistência, até o início do governo Figueiredo, aos ditames do FMI). O sistema de interesses hegemônicos do período militar estava, portanto, composto pelo grande capital monopolista, o capital bancário e a burguesia interna. A força que dirigia esse sistema hegemônico tendia a ser aquela que se encontrava na interseção dessas múltiplas dimensões do capital, qual seja, a grande burguesia monopolista bancária interna. 
Mas isso não significa que a cada momento do processo de tomada de decisões na política econômica a força diretriz do capital estivesse diretamente presente na cena política. Nem tampouco a sua presença como força social devia fazer-se sempre pelos mesmos representantes políticos. Em parte, observando-se o conjunto das decisões de política econômica ao longo dos governos militares, o núcleo estratégico da burocracia do Estado desempenhava o papel de representar os interesses gerais da força dirigente. Em outros momentos, como naqueles de escolha ou substituição dos ministros das pastas principais da área econômica, surgiam no cenário os representantes diretos da fração dirigente - Febraban (Federação Brasileira de Bancos), grupo parlamentar.

Poder-se-ia objetar que nem sempre se pode inferir do leque de políticas governamentais as relações de forças vigentes no seio do bloco no poder (e vice-versa). É certo que se constata na história das sociedades capitalistas algumas situações em que o poder de pressão econômica de uma fração de classe não se traduz em força política, ou seja, em capacidade de fazer valer os seus interesses no seio das políticas governamentais. Foi o caso da ascensão dos governos antimonopolistas no início da redemocratização de Portugal e da Grécia na década de 1970. Mas esses momentos de dissociação entre a força econômica e a hegemonia política tendem a ser breves. A médio e longo prazos, a tendência é que a natureza da política governamental corresponda aos interesses da fração economicamente preponderante no interior do bloco no poder.

Poder-se-ia indagar também se não há uma certa circularidade no argumento que afirma a correlação entre a política governamental e a configuração do bloco no poder, no sentido de que se tal política determina a emergência, articulação, dissolução dos interesses das frações, ao mesmo tempo a capacidade de pressão de tais agrupamentos de interreses junto à burocracia do Estado parece jogar um papel importante na definição da própria política estatal. Ao meu ver, o risco de circularidade é afastado se se adota uma abordagem que leve em conta os dois planos para os quais a expressão "fração de classe" remete: de um lado, à fração "potencial", "virtual" ou "em si”" e, de outro lado, à fração "efetiva", "existente" ou "para si”". 
É enquanto agrupamento potencial, ou seja, como um efeito da estrutura econômica, que a fração teria um papel importante na definição da política governamental, estabelecendo em certa conjuntura os limites para as políticas ou um padrão geral de política. Nesse sentido, jogariam um papel secundário para o estabelecimento desse padrão de política os fatores tais como a origem e as afinidades sociais do núcleo dirigente da burocracia do Estado. Já a fração enquanto agrupamento factual está orientada em larga medida pelo tipo de política prevalecente na conjuntura. Nesse sentido, inclusive representantes míopes da fração hegemônica podem se chocar com a burocracia estatal, a despeito de essa defender os interesses gerais de tal fração.

Em síntese, seriam duas as considerações básicas para se compreender a questão do fracionamento da classe dominante. Em primeiro lugar, é preciso levar em conta que a fração de classe se enraíza simultaneamente nas estruturas da totalidade social. Fica difícil assim sustentarem-se as hipóteses de fração exclusivamente política ou fração estritamente econômica. Em segundo lugar, as políticas governamentais atuam como fator estratégico que agrega e articula os interesses das frações de classe dominante. A natureza das medidas de políticas econômica e social correlaciona-se à configuração do fracionamento de classe na cena política.

Por fim, uma avaliação da tese segundo a qual o capitalismo contemporâneo teria levado ao fim das frações do capital exigiria uma análise mais ampla do que a constatação de certos fenômenos tais como a existência de conglomerados empresariais multifuncionais ou de empresas transnacionais. Seria preciso ver, por exemplo, até que ponto o grupo de empresas multifuncionais não continuaria sendo polarizado e dividido pelos interesses das empresas especializadas, ou seja, das frações do capital. Seria preciso averiguar também se as empresas verdadeiramente transnacionais (como no modelo joint venture) constituiriam uma força dominante no cenário mundial. 